\title{
Efeito de fungos micorrízicos arbusculares na bioprodução de fenóis totais e no crescimento de Passiflora alata Curtis
}

RITER NETTO, A.F.; FREITAS M.S.M.*; MARTINS, M.A.; CARVALHO, A.J.C.; VITORAZI FILHO, J.A. Universidade Estadual do Norte Fluminense Darcy Ribeiro. Centro de Ciências e Tecnologias Agropecuárias, Laboratório de Solos. Av. Alberto Lamego, 2000, CEP: 28013-602, Campos dos Goytacazes-Brasil *msimone@ uenf.br.

\begin{abstract}
RESUMO: Os compostos fenólicos encontrados no extrato das folhas de maracujazeiro doce (Passiflora alata Curtis) são os principais responsáveis pelos efeitos terapêuticos, incluindo a atividade ansiolítica. $O$ presente trabalho avaliou o efeito de diferentes espécies de fungo micorrízicos arbusculares (FMAs) e doses de fósforo sobre a bioprodução de fenóis totais, bem como, o crescimento vegetal e os conteúdos de nitrogênio, fósforo e potássio na massa da matéria seca da parte aérea do maracujazeiro doce. O experimento, fatorial $4 \times 2$, foi conduzido em um telado com quatro tratamentos microbiológicos: Glomus etunicatum, Glomus intraradices, inóculo misto (Glomus clarum e Gigaspora margarita) e o controle sem fungo, e duas doses de fósforo: 0 e $50 \mathrm{mg} \mathrm{kg}^{-1}$ de solo. $\mathrm{O}$ delineamento experimental foi de blocos casualizados com quatro repetições. As plantas foram colhidas 90 dias após a semeadura. Na ausência da adubação fosfatada, o conteúdo de fenóis totais, a massa da matéria seca da parte aérea e o número de folhas foram maiores nos tratamentos inoculados com FMAs, quando comparados ao tratamento sem fungo. Plantas com inóculo misto apresentaram maior altura com ou sem adubação fosfatada. Os tratamentos inoculados com FMAs, tanto na dose 0 quanto na dose 50 $\mathrm{mg} \mathrm{kg}^{-1}$ de $\mathrm{P}$ incrementaram os conteúdos de $\mathrm{N}, \mathrm{P}$ e K na parte aérea do maracujazeiro doce, evidenciando a capacidade dos FMAs em promover o melhor estado nutricional das plantas.
\end{abstract}

Palavras-chave: compostos fenólicos, maracujazeiro doce, micorrizas

\begin{abstract}
Total phenols in Passiflora alata Curtis inoculated with mycorrhizal fungi. The phenolic compounds found in extracts from leaves of sweet passion fruit (Passiflora alata) are mainly responsible for its therapeutic effects, such as the anxiolytic activity. This study evaluated the effects of different species of mycorrhizal fungi (AMF) and phosphorus levels on the bioproduction of total phenols, as well as plant growth and the contents of nitrogen, phosphorus and potassium in the dry mass of shoots of sweet passion fruit. The experiment was conducted in a greenhouse. The factors were arranged in a :[(microbiological treatments: Glomus etunicatum, Glomus intraradices, mixed inoculum (Glomus clarum and Gigaspora margarita) and without fungus] $\times 2$ (doses of phosphorus: 0 and $50 \mathrm{mg} \mathrm{kg}^{-1}$ soil) factorial arrangement, in a randomized block experimental design with four replications. The plants were harvested 90 days after seeding. In the absence of phosphate fertilization, the total phenol content, dry mass of shoot and leaf number were greater in treatments inoculated with AMF compared to the treatments without fungus. Mixed inoculum plants had higher plant height with or without phosphate fertilization. Treatments inoculated with AMF in both the 0 and $50 \mathrm{mg} \mathrm{kg}^{-1}$ doses of $\mathrm{P}$ increased the content of $\mathrm{N}, \mathrm{P}$ and $\mathrm{K}$ in the shoots of sweet passion fruit, demonstrating the ability of AMF to promote better nutritional statusfin plants.
\end{abstract}

Keywords: phenolic compounds, sweet passion fruit, mycorrhizae

\section{INTRODUÇÃO}

Diferentemente das fruteiras tropicais de maior importância, o maracujazeiro pertence a um gênero muito diversificado em espécies frutíferas.

Das 519 espécies de Passiflora inventariadas, 81 possuem fruto comestível. Entretanto, deste total, somente algumas espécies alcançaram o cultivo

Recebido para publicação em 28/04/2010 
com fins comerciais, dentre essas a Passiflora alata Curtis (Coppens \& Eeckenbrugge, 2003).

A espécie Passiflora alata Curtis é a segunda espécie de importância econômica no Brasil, particularmente no Estado de São Paulo (Manica, 2005). Os frutos são consumidos das mais variadas formas, in natura ou na fabricação de doces, a planta apresenta potencial para atender várias opções de mercado, tais como o de plantas ornamentais e o farmacêutico.

No Brasil, foi aprovado pelo Governo, em fevereiro de 2009, a Relação Nacional de Plantas Medicinais de Interesse ao SUS (RENISUS), uma lista com 71 espécies, entre elas as espécies Passiflora alata, Passiflora edulis e Passiflora incarnata (Ministério da Saúde, 2009). As folhas de $P$. alata e $P$. edulis possuem atividade ansiolítica, tanto em extrato hidroalcoólico, como em extrato aquoso (Petry et al., 2001; Paris et al., 2002; Provensi, 2007). Os compostos fenólicos encontrados nos extratos das folhas estão entre os principais responsáveis pelos efeitos terapêuticos. Betti et al., (2004) demonstraram o envolvimento dos flavonóides na atividade ansiolítica da espécie de Passiflora alata Curtis.

Relacionado às plantas, têm sido demonstrado o efeito benéfico dos fungos micorrízicos arbusculares (FMAs) nas mais variadas condições e espécies vegetais, na maioria dos casos, estimulando o crescimento vegetal como conseqüência do efeito sobre a nutrição da planta, principalmente no aumento da absorção de fósforo (P) (Bressan et al., 2001; Freitas et al., 2006; Smith \& Read, 2008).

A biossíntese dos metabólitos secundários e, conseqüentemente, dos princípios ativos em plantas depende de fatores genéticos, fisiológicos e ambientais. Uma estratégia para se aumentar a bioprodução desses compostos, é o cultivo dessas plantas sob fatores ambientais importantes, como a inoculação com FMAs e a adubação fosfatada (Freitas et al., 2004a e b; Kapoor et al., 2007; Toussaint et al., 2007). No entanto, para a espécie Passiflora alata Curtis, não se conhece a influência dos FMAs e da adubação fosfatada quanto a bioprodução dos compostos fenólicos de interesse.

Nesse contexto, o presente trabalho teve como objetivo avaliar os efeitos de diferentes espécies de fungo micorrízicos arbusculares (FMAs) e de doses de fósforo sobre a bioprodução de fenóis totais, bem como, o crescimento vegetal e o conteúdo de nitrogênio, fósforo e potássio na massa seca da parte aérea do maracujazeiro doce.

\section{MATERIAL E MÉTODOS}

\section{Local do experimento e delineamento experimental}

O experimento com Passiflora alata Curtis foi realizado em telado construído com sombrite preto $(50 \%)$, protegido com plástico transparente de 150 micras na parte superior, e conduzido na Universidade Estadual do Norte Fluminense Darcy Ribeiro, localizada em Campos dos Goytacazes, RJ (Latitude = 21019'23“S; Longitude = 41010'40” W; Altitude $=14 \mathrm{~m}$ ), no período de agosto a novembro de 2007. Durante a condução do experimento, a temperatura mínima diária apresentou variações entre 15,0 e $28,0^{\circ} \mathrm{C}$, com média das mínimas igual a $19,2^{\circ} \mathrm{C}$, sendo que a temperatura máxima diária apresentou variações entre 24,0 e $39,0^{\circ} \mathrm{C}$ com média das máximas igual a $32,2^{\circ} \mathrm{C}$.

Os tratamentos foram arranjados no modelo fatorial $4 \times 2$ [4 tratamentos microbiológicos: Glomus etunicatum (Becker \& Gerdeman); Glomus intraradices (Schenck \& Smith); inóculo misto (Glomus clarum Nicolson \& Schenck e Gigaspora margarita Becker \& Hall) e sem fungo], e 2 (doses de fósforo: 0 e $50 \mathrm{mg}$ de $\mathrm{P} \mathrm{kg}{ }^{-1}$ de solo), no delineamento experimental de blocos casualizados, com quatro repetições. A unidade experimental foi composta por um vaso plástico contendo $4 \mathrm{~kg}$ de substrato e três plantas por vaso.

\section{Preparo do inóculo e do substrato}

Antes da implantação do experimento foi realizada a multiplicação do inóculo, sendo que o substrato utilizado, uma mistura de solo e areia 1:2 $(\mathrm{v} / \mathrm{v})$, foi esterilizado em autoclave por duas vezes, a $121^{\circ} \mathrm{C}$, por 1 hora. Ao substrato, colocado em vasos com capacidade de $3 \mathrm{~kg}$, foram adicionados $50 \mathrm{~g}$ de inóculo inicial, constituindo uma mistura de solo contendo esporos, hifas, e raízes colonizadas com o fungo de cada espécie a ser estudada, Glomus clarum, Gigaspora margarita, Glomus intraradices e Glomus etunicatum. O inóculo inicial dos fungos, contendo esporos, hifas e raízes finas cortadas, foi obtido da coleção do Setor de Microbiologia do Solo da UENF, depósito $n^{\circ} 2$ (Inóculo misto), $n^{\circ} 3$ (Glomus etunicatum) e ${ }^{\circ} 5$ (Glomus intraradices). A seguir, 15 sementes de Brachiaria brizantha cultivar MG-5, semente comercial da safra 2005/2006, desinfestadas com solução $0,5 \%$ de hipoclorito de sódio durante 10 min e lavadas com água deionizada, foram semeadas em cada vaso. Quatro meses após a semeadura, a parte aérea foi cortada e trinta dias após o corte, a mistura de solo foi utilizada como inóculo.

O substrato utilizado para o experimento foi composto por solo, classificado como Cambissolo Háplico Tb Distrófico típico (Embrapa, 2006),

Rev. Bras. Pl. Med., Campinas, v.16, n.1, p.1-9, 2014. 
coletado na profundidade de $0-20 \mathrm{~cm}$ e peneirado e misturado com areia na proporção 1:2 (v/v) e esterilizado em autoclave por 2 vezes, a temperatura de $121^{\circ} \mathrm{C}$, por 1 hora. Após a autoclavação, o substrato apresentou as características químicas de $\mathrm{pH}$ em água $=6,5$; matéria orgânica $=7,24 \mathrm{~g} \mathrm{dm}^{-3} ; \mathrm{P}=$ $9,0 \mathrm{mg} \mathrm{dm}^{-3} ; \mathrm{S}=14,0 \mathrm{mg} \mathrm{dm}^{-3} ; \mathrm{K}^{+}=0,7 \mathrm{mmol}_{\mathrm{cm}} \mathrm{dm}^{-3}$; $\mathrm{Ca}^{2+}=16,7 \mathrm{mmol}_{\mathrm{c}} \mathrm{dm}^{-3} ; \mathrm{Mg}^{2+}=10,7 \mathrm{mmol}_{\mathrm{c}} \mathrm{dm}^{-3} ; \mathrm{Al}^{3+}=$ $0,0 \mathrm{mmol}_{\mathrm{c}} \mathrm{dm}^{-3} ; \mathrm{H}+\mathrm{Al}=1,3 \mathrm{mmol}_{\mathrm{c}} \mathrm{dm}^{-3} ; \mathrm{SB}=28,6$ $\mathrm{mmol}_{\mathrm{c}} \mathrm{dm}^{-3} ; \mathrm{T}=29,90 \mathrm{mmol}_{\mathrm{c}} \mathrm{dm}^{-3} ; \mathrm{Fe}=39,3 \mathrm{mg} \mathrm{dm}^{-}$ 3. $\mathrm{Cu}=0,47 \mathrm{mg} \mathrm{dm}^{-3} ; \mathrm{Zn}=1,92 \mathrm{mg} \mathrm{dm}^{-3} ; \mathrm{Mn}=108,9$ $\mathrm{mg} \mathrm{dm}^{-3}$ e $\mathrm{B}=0,73 \mathrm{mg} \mathrm{dm}^{-3}$.

Para a correção química do substrato, foi adicionando $\mathrm{K}\left(92,7 \mathrm{mg} \mathrm{kg}^{-1}\right)$ na dose 0 de $\mathrm{P}$, utilizando-se $\mathrm{KCl}$ em solução aquosa como fonte de $\mathrm{K}$. Na dose 50 de $\mathrm{P}$ foi adicionado $\mathrm{K}(92,7 \mathrm{mg}$ $\left.\mathrm{kg}^{-1}\right)$ e $\mathrm{P}\left(50 \mathrm{mg} \mathrm{kg}^{-1}\right)$, utilizando $\mathrm{KH}_{2} \mathrm{PO}_{4}$ e KCl como fontes de $\mathrm{P}$ e K para a correção Depois de corrigido, o solo foi mantido por 15 dias incubado, devidamente molhado, sendo posteriormente realizadas as extrações de $\mathrm{P}\left(\right.$ Mehlich $\left.^{-1}\right)$ no substrato. Os teores de $P$, nas doses 0 e 50 , foram 8,7 e $35 \mathrm{mg} \mathrm{kg}^{-1}$ de $P$, respectivamente. Foi realizada adubação nitrogenada, utilizando como fonte $\mathrm{NH}_{4} \mathrm{NO}_{3}(20 \mathrm{mg}$ $\mathrm{kg}^{-1}$ de N).

\section{Inoculação e plantio}

O material propagativo utilizado foi constituído de sementes obtidas de frutos de maracujá doce, adquirido no comércio de Campos dos Goytacazes-RJ, cuja origem de produção foi a região de Campinas-SP. O tratamento para a quebra de dormência foi realizado pela escarificação com areia e imersão em ácido giberélico ( $\left.300 \mathrm{mg} \mathrm{L}^{-1}\right)$ por 24 horas, de acordo com metodologias descritas por Martins et al. (2003) e D'Eça et al. (2003). Antes da semeadura foram adicionados $50 \mathrm{~g}$ do solo com inóculo das espécies FMAs nos tratamentos correspondentes a cada tipo de inóculo, que foram colocados a 2-3 cm abaixo da superfície do solo. Então em cada vaso foram colocadas 20 sementes por vaso. As plantas foram irrigadas diariamente com água deionizada. Aos 30 dias foi realizado o primeiro desbaste, permanecendo em cada vaso as 10 plantas mais vigorosas e, aos 40 dias, foram deixadas 3 plantas por vaso.

\section{Avaliações e análise estatística}

As plantas foram colhidas noventa dias após a semeadura quando foi determinado: altura, número de folhas, massa da matéria seca da parte aérea, e porcentagem de colonização micorrízica nas raízes. Na parte aérea foi determinado os teores de $\mathrm{N}, \mathrm{P}, \mathrm{K}$ e fenóis totais.

A medição da altura foi realizada com o auxílio de régua milimetrada, desde o colo da planta ao ápice do ramo principal. A parte aérea foi seca em estufa de ventilação forçada, a temperatura de $40^{\circ} \mathrm{C}$ por 10 dias, após esse período foi determinada a massa seca.

Para determinar a porcentagem de colonização micorrizica, raízes finas foram coletadas, lavadas, cortadas em aproximadamente $2 \mathrm{~cm}$ de comprimento e armazenadas em álcool etílico $50 \%$ para posterior avaliação da porcentagem de colonização radicular. Para determinar a porcentagem de colonização micorrízica das raízes, estas foram coloridas segundo Grace \& Stribley (1991), com as seguintes adaptações, $\mathrm{KOH} 5 \%$ a $80^{\circ} \mathrm{C}$. As raízes foram levadas ao microscópio para observação da presença de estruturas de FMAs.

A parte aérea seca foi moída em moinho do tipo Willey e armazenada em frasco hermeticamente fechado para a determinação do teor de nitrogênio $(\mathrm{N})$, fósforo $(\mathrm{P})$ e potássio $(\mathrm{K})$ e fenóis totais. Para a determinação de $\mathrm{N}, \mathrm{P}$ e K, o material vegetal foi submetido à oxidação pela digestão sulfúrica obtendo-se o extrato, no qual foi analisado o nitrogênio pelo método de Nessler (Jackson, 1965), o fósforo pelo método colorimétrico do molibdato (Jones Jr. et al., 1991), e o potássio por espectrofotometria de emissão de chama (Malavolta et al., 1997).

A determinação dos fenóis totais foi realizada pelo método de Folin-Dennis (Anderson e Ingram, 1993). Para a obtenção dos extratos pesou-se $0,75 \mathrm{~g}$ do material vegetal seco e moído em um tubo, adicionou-se $20 \mathrm{~mL}$ de metanol $50 \%$, e aqueceu em banho-maria à $80{ }^{\circ} \mathrm{C}$ por 1 hora. Nessa etapa foi colocado, junto aos tubos com as amostras, um tubo com $20 \mathrm{~mL}$ de metanol 50\% sem amostra (branco da análise). Após o resfriamento os extratos foram filtrados e transferidos para tubos de $50 \mathrm{ml}$ utilizando metanol $50 \%$ para lavagem. Para determinação do teor de fenóis totais foi pipetado uma alíquota de $0,2 \mathrm{~mL}$ do extrato e adicionou-se a este $7,3 \mathrm{~mL}$ de água deionizada, $0,5 \mathrm{~mL}$ de reagente Folin-Dennis e $2,0 \mathrm{~mL}$ de carbonato de sódio $17 \%$. Estes foram agitados e após 20 minutos foi realizada a leitura em espectrofotômetro Uv/visível, marca Hitachi U-2000, no comprimento de onda de $760 \mathrm{~nm}$. Para a curva analítica padrão foi utilizado ácido tânico em solução de $100 \mathrm{mg} \mathrm{L}^{-1}$ nas concentrações 0, 2, 4, 6, 8 e $10 \mathrm{mg} \mathrm{L}^{-1}$ adicionando $0,5 \mathrm{~mL}$ de reagente Folin-Dennis, $2,0 \mathrm{~mL}$ de carbonato de sódio $17 \%$ e completando o volume final para 10 $\mathrm{mL}$ com água. Para a determinação do conteúdo de fenóis totais multiplicamos a massa seca de cada planta pelo seu teor.

Os dados foram submetidos à análise de variância e quando houve significância foi utilizado o teste de Tukey a $5 \%$ de probabilidade, utilizando o programa de estatística SANEST. 


\section{RESULTADO E DISCUSSÃO}

Verifica-se na Tabela 1 , com resumo das análises de variâncias, que ocorreu efeito significativo, para todas as variáveis analisadas, da interação entre as doses de fósforo e os tratamentos microbiológicos (fungos).

O número de folhas, a altura e a massa da matéria seca da parte aérea do maracujazeiro doce apresentaram os maiores valores (11,9 folhas por planta, 18,3 cm e 1,96 g por planta, respectivamente) em plantas inoculadas com inóculo misto e adubadas com 50 mg de $\mathrm{P} \mathrm{kg}^{-1}$ de solo e os menores valores (6,9 folhas por planta; 4,8 cm e 0,21 g por planta, respectivamente) em plantas não inoculadas com FMAs e cultivadas em solo que não receberam adubação fosfatada (Tabela 2 ).

Na ausência da adubação fosfatada, a produção de massa da matéria seca da parte aérea nos tratamentos microbiológicos com inóculo misto (G. clarum e G. margarita), G. etunicatum e G. intraradices foram superiores ao tratamento sem fungo em 695, 752 e 680\%, respectivamente (Tabela 2). Estes mesmos tratamentos também proporcionaram aumento no número de folhas, correspondendo a 66, 60 e 58\%, respectivamente, em relação ao tratamento sem fungo (Tabela 2 ).

Verifica-se que a adubação fosfatada, diferente do que ocorreu para altura de plantas e massa da matéria seca da parte aérea, promoveu aumento do número de folhas quando as plantas não foram micorrizadas (Tabela 2). Foi evidenciado que a menor média nos tratamentos micorrizados proporcionou incremento de 5,52\% para o número de folhas (inóculo misto), $26,28 \%$ para altura de plantas e de $55,2 \%$ para massa seca da parte aérea (plantas inoculadas com Glomus intraradices) em relação ao tratamento sem fungo. É provável que o menor fornecimento de fosforo as plantas, na ausência da micorrização, conforme se verifica nos teores e conteúdo de P apresentados na Tabela 4, tenha sido o suficiente para manter a emissão de folhas em valores semelhantes aos tratamentos micorrizados, mas insuficiente para a expansão foliar nos mesmos níveis.

Para a altura de plantas, quando não se utilizou adubação fosfatada, todos os tratamentos inoculados foram superiores ao tratamento sem fungo, destacando-se o inóculo misto que foi superior aos demais tratamentos inoculados e que proporcionou um incremento de $268 \%$ quando comparado com o tratamento onde as plantas não foram inoculadas (Tabela 2). Estes resultados demonstram a eficiência da inoculação com fungos micorrízicos em promover o crescimento das mudas de maracujazeiro doce, sem adubação fosfatada. As associações micorrízicas são reconhecidas por sua habilidade em estimular o crescimento de plantas, principalmente por meio do incremento na absorção de nutrientes como o fósforo (Smith \& Read, 2008). O estabelecimento da simbiose micorrízica é determinado por fatores edafoclimáticos e

TABELA 1. Resumo da análise de variância e dos correspondentes coeficientes de variação (CV) para as características $\mathrm{N}^{\circ}$ de folhas, altura de plantas, massa da matéria seca da parte aérea, colonização micorrízica em raízes, teor e conteúdo de fenóis totais, teor e conteúdo de $\mathrm{P}$ e conteúdo de $\mathrm{K}$ e $\mathrm{N}$ de maracujazeiro doce em função da inoculação com fungos micorrízicos e de adubação fosfatada.

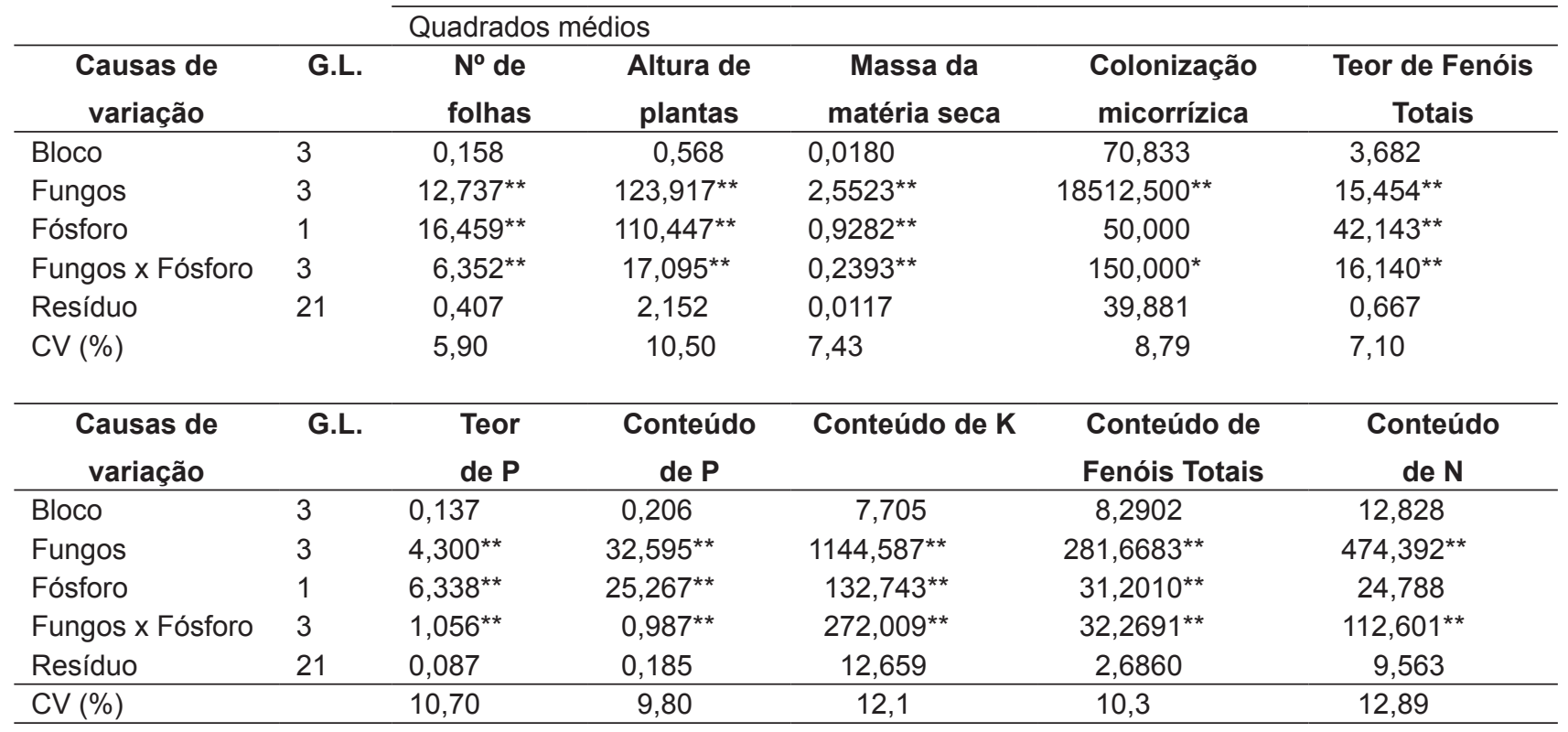

${ }^{*} \mathrm{e}^{* *}$ significativo a 1 e $5 \%$ de probabilidade, respectivamente, pelo teste de $\mathrm{F}$. 
TABELA 2. Número de folhas, altura de plantas, massa da matéria seca da parte aérea e colonização micorrízica em raízes de maracujazeiro doce em função da inoculação com fungos micorrízicos e de adubação fosfatada.

\begin{tabular}{|c|c|c|c|c|c|c|c|c|}
\hline \multirow[t]{3}{*}{ Fungo } & \multicolumn{2}{|c|}{$\begin{array}{l}\mathrm{N}^{\circ} \text { de folhas por } \\
\text { planta }\end{array}$} & \multicolumn{2}{|c|}{$\begin{array}{l}\text { Altura de plantas } \\
\qquad(\mathrm{cm})\end{array}$} & \multicolumn{2}{|c|}{$\begin{array}{c}\text { Massa da matéria } \\
\text { seca } \\
\left.\text { (g planta-1 }^{-1}\right) \\
\end{array}$} & \multicolumn{2}{|c|}{$\begin{array}{c}\text { Colonização } \\
\text { micorrízica } \\
(\%)\end{array}$} \\
\hline & \multicolumn{2}{|c|}{$\mathrm{P}\left(\mathrm{mg} \mathrm{kg}^{-1}\right)$} & \multicolumn{2}{|c|}{$\mathrm{P}\left(\mathrm{mg} \mathrm{kg}^{-1}\right)$} & \multicolumn{2}{|c|}{$\mathrm{P}\left(\mathrm{mg} \mathrm{kg}^{-1}\right)$} & \multicolumn{2}{|c|}{$\mathrm{P}\left(\mathrm{mg} \mathrm{kg}^{-1}\right)$} \\
\hline & 0 & 50 & 0 & 50 & 0 & 50 & 0 & 50 \\
\hline Inoculo misto & $11,4 \mathrm{aA}$ & $11,5 \mathrm{aA}$ & 17,7 aA & 18,3 aA & $1,67 a b B$ & $1,96 \mathrm{aA}$ & $95 \mathrm{aA}$ & $100 \mathrm{aA}$ \\
\hline G. etunicatum & $11,1 \mathrm{aA}$ & $11,8 \mathrm{aA}$ & $12,7 \mathrm{bB}$ & $17,0 \mathrm{aA}$ & $1,79 \mathrm{aA}$ & $1,84 \mathrm{aA}$ & $98 \mathrm{aA}$ & $82 \mathrm{bB}$ \\
\hline G. intraradices & $10,9 \mathrm{aA}$ & $11,9 a A$ & $13,2 \mathrm{bB}$ & $15,6 \mathrm{aA}$ & $1,46 \mathrm{bB}$ & $1,63 \mathrm{bA}$ & $100 \mathrm{aA}$ & $100 \mathrm{aA}$ \\
\hline Sem fungo & $6,9 \mathrm{bB}$ & $10,9 \mathrm{aA}$ & $4,8 \mathrm{cB}$ & $12,3 \mathrm{bA}$ & $0,21 \mathrm{cB}$ & $1,05 \mathrm{cA}$ & $0 \mathrm{bA}$ & $0 \mathrm{cA}$ \\
\hline
\end{tabular}

Médias seguidas pela mesma letra minúscula na coluna e letra maiúscula na linha não diferem entre si, pelo teste de Tukey a $5 \%$.

aspectos da relação fungo-planta, a utilização de diferentes espécies e/ou isolados de FMAs, resultam em respostas diferenciadas por parte do hospedeiro (Costa et al., 2001; Cavalcante et al., 2002). Nesse sentido, Silva et al., (2004), testando diferentes espécies de FMAs (Acaulospora longula, Gigaspora albida, Glomus etunicatum e Scutellospora heterogama) em mudas de maracujazeiro doce, observaram que aos 90 dias após a inoculação, a espécie G. albida proporcionou incrementos significativos de $1.430,751$ e $751 \%$ na massa da matéria seca foliar, altura, e número de folhas, respectivamente, em relação ao tratamento controle. Esses autores encontraram no melhor tratamento inoculado, $1,53 \mathrm{~g}$ de massa da matéria seca da parte aérea; $10,68 \mathrm{~cm}$ de altura e 12,77 folhas por planta. Esses valores estão dentro dos valores encontrados nesse trabalho para massa da matéria seca da parte aérea, altura e número de folhas.

Resultados obtidos por Cavalcante et al., (2002) demonstraram o benefício da inoculação com FMAs no crescimento das espécies do gênero Passiflora, plantas de Passiflora edulis aos 50 dias, inoculadas com G. albida, G. margarita e $G$. etunicatum, foram superiores aos demais tratamentos. Dentre estes, o G. etunicatum proporcionou incrementos de $260 \%$ na altura, de $93 \%$ no número de folhas e $4.266 \%$ na massa da matéria seca da parte aérea.

O incremento obtido no presente trabalho no crescimento das plantas de maracujazeiro doce com a inoculação de FMAs é de grande interesse, pois demonstram a capacidade dos FMAs em potencializar a produção de mudas de maracujazeiro, reduzindo a aplicação de insumos químicos, principalmente $P$, necessários para esta cultura. A associação mutualística formada entre os fungos micorrízicos arbusculares (FMAs) e as raízes de frutíferas tem importância, pois essas passam por fase de viveiro, antecipando o tempo de transplantio para o campo, estimulando o crescimento precoce da muda e conseqüentemente, reduzindo o seu tempo de aclimatação, o que aumenta a produtividade, a rotatividade na ocupação da infraestrutura e a eficiência de utilização da mãode-obra especializada. Esses benefícios foram observados em algumas frutíferas como Passiflora edulis (Cavalcante et al., 2002), Passiflora alata (Anjos et al., 2005) e Anacardium occidentale (Weber et al., 2004).

A colonização micorrízica variou de $82 \%$ para G. etunicatum a $100 \%$ nos tratamentos com inóculo misto e G. intraradice (Tabela 2). A colonização micorrízica nas raízes das plantas inoculadas com $G$. etunicatum foi reduzida com a adição de $P$, sendo a média do tratamento com adubação fosfatada $16 \%$ menor que no tratamento sem adubação, verificando o efeito negativo da adição de fósforo para simbiose de G. etunicatum em maracujazeiro doce. De acordo com Nogueira \& Cardoso (2000), o aumento de $\mathrm{P}$ pode ter influência negativa sobre o micélio externo ativo do fungo micorrízico. Resultados semelhantes foram encontrados por Silva, (2008) em plantas de Passiflora cincinnata e Passiflora setacea inoculadas com $G$. etunicatum, sendo que nas plantas de $P$. setacea a colonização micorrízica reduziu de $24,14 \%$ no tratamento sem $P$ para $10,37 \%$ no tratamento com adição de $P$.

$O$ efeito negativo das doses de $P$ na percentagem de colonização radicular de FMAs também foi observado na associação de $G$. intraradices com plantas de Citrus limonia Osbeck (Melloni et al., 2000). Alguns autores destacaram hipóteses relacionadas, como a redução da exsudação radicular pela interferência no desenvolvimento micelial (Miranda \& Harris, 1994); a restrição da infecção micorrízica pela redução da permeabilidade da membrana das células das raízes (Miranda et al., 1989); e a variação do fluxo de carbono do hospedeiro ao endófito (Siqueira et al., 1984). Em adição, o balanço hormonal da planta pode ser influenciado pelas condições ambientais, principalmente pela concentração de $\mathrm{P}$, explicando parcialmente o efeito de fósforo no desenvolvimento das micorrizas (Kiriachek et al., 2009). 
Os valores das variáveis teor e conteúdo de fenóis totais na parte aérea das plantas de maracujazeiro doce em função da inoculação com fungos micorrízicos e de adubação fosfatada são mostrados na Tabela 3 , em que se verifica o efeito significativo da interação entre as doses de fósforo e as espécies de fungos micorrízicos. O teor médio de fenóis totais encontrado na parte aérea das plantas de maracujazeiro doce foi $11,5 \mathrm{~g} \mathrm{~kg}^{-1}$, com variações entre 9,7 e $16,8 \mathrm{~g} \mathrm{~kg}^{-1}$ entre os tratamentos.

Sem adição de fósforo, o conteúdo de fenóis totais foi maior nos tratamentos inoculados com FMAs, quando comparados ao tratamento sem fungo (Tabela 3). As maiores médias foram observadas nos tratamentos inoculados com inóculo misto $\left(20,4 \mathrm{mg}\right.$ planta $\left.^{-1}\right)$ e $\mathrm{G}$. etunicatum $(19,3 \mathrm{mg}$ planta $^{-1}$ ) que proporcionaram incrementos de $482 \mathrm{e}$ $451 \%$, respectivamente em relação ao tratamento sem fungo. Com adição de $P$, não houve incremento no conteúdo de fenóis totais nos tratamentos inoculados com FMAs, entretanto no tratamento sem fungo houve incremento de $211 \%$. O maior acúmulo dos metabólitos secundários, como fenóis, óleos essenciais e esteviosídeos foram observados em plantas micorrizadas, com Baccharis trimera (Freitas et al., 2004b), Mentha arvensis L. (Freitas et al., 2006) e Stevia rebaudiana (Portugal, 2006), respectivamente.

Na ausência da adubação fosfatada os teores de fenóis totais foram maiores no tratamento sem fungo, quando comparados aos tratamentos inoculados (Tabela 3). Plantas deficientes em fósforo acumulam carboidratos, ocorrendo um desvio da rota para formação do ácido chiquímico (Taiz e Zeiger, 2008). Freitas et al. (2008), trabalhando com deficiência de macronutrientes em Passiflora alata, observaram que a deficiência de $\mathrm{P}$ aumentou $16 \%$ os teores de vitexina nas folhas, em relação ao tratamento completo. No presente trabalho, o teor médio de $P$ no tratamento sem fungo e sem fósforo foi igual a $0,68 \mathrm{~g} \mathrm{~kg}^{-1}$ (Tabela 4), valores considerados baixos para a espécie de Passiflora alata, ou seja, nesse tratamento as plantas estavam deficientes em $\mathrm{P}$, enquanto nos outros tratamentos inoculados e sem fósforo os teores de $P$ foram adequados para a espécie em estudo $\left(2,6 \mathrm{~g} \mathrm{~kg}^{-1}\right)$. Apesar dos maiores teores de fenóis totais serem obtidos no tratamento sem fungo e sem adubação fosfatada, o maior rendimento por planta foi obtido no tratamento inoculado com inóculo misto com adição de $\mathrm{P}\left(20,9 \mathrm{mg}\right.$ planta $\left.^{-1}\right)$ e sem adição de $\mathrm{P}$ $\left(20,4\right.$ mg planta $\left.^{-1}\right)$.

Os teores de fenóis totais foram reduzidos nos tratamentos inoculados com $G$. etunicatum e no tratamento sem fungo, quando o fósforo foi adicionado ao sistema (Tabela 3). Para o tratamento inoculado com $G$. etunicatum, a redução no teor de fenóis totais com a adição de fósforo pode estar relacionada com a diminuição da colonização micorrízica nas raízes por esta espécie de fungo (Tabela 2), pois, segundo Moreira \& Siqueira (2002), plantas inoculadas com fungos podem estimular a síntese da enzima fenilalanina amonialiase, que regula a produção dos metabolitos formados pela via do chiquimato, resultando no aumento da síntese dos compostos fenólicos.

Soares et al., (2005), trabalhando com plantas de Passiflora edulis inoculadas com FMAs, observaram o incremento de compostos fenólicos nas raízes, possivelmente flavonoides, nos tratamentos inoculados com inoculo nativo e G. clarum e adubados com $50 \mathrm{mg} \mathrm{kg}^{-1}$ de P. Freitas et al., (2004a) verificaram em plantas de Baccharis trimera que a inoculação com $G$. etunicatum proporcionou incrementos nos teores de fenóis totais nas folhas.

As folhas de Passiflora alata apresentaram redução de $73 \%$ nos teores de fenóis totais no tratamento sem fungo e com adição de $P(9,7 \mathrm{~g}$ $\mathrm{kg}^{-1}$ ) em relação ao tratamento sem fungo e sem $P\left(16,8 \mathrm{~g} \mathrm{~kg}^{-1}\right)$ (Tabela 3). Mendes et al., (2005) observaram que o aumento na concentração de fósforo em solução nutritiva reduziu em $20 \%$ o teor de flavonóides nas folhas de Dimorphandra mollis.

Foram observados maiores conteúdos de $\mathrm{N}, \mathrm{P}$ e $\mathrm{K}$ e teores de $\mathrm{P}$ nos tratamentos inoculados com FMAs, com e sem adição de fósforo, quando comparados ao tratamento sem fungo (Tabela 4),

TABELA 3. Teor e conteúdo de fenóis totais em plantas de maracujazeiro doce em função da inoculação com fungos micorrízicos e da adubação fosfatada.

\begin{tabular}{|c|c|c|c|c|}
\hline \multirow{4}{*}{ Fungo } & \multirow{2}{*}{\multicolumn{2}{|c|}{$\begin{array}{l}\text { Teor de Fenóis Totais } \\
\left(\mathrm{g} \mathrm{kg}^{-1}\right)\end{array}$}} & \multirow{2}{*}{\multicolumn{2}{|c|}{$\begin{array}{l}\text { Conteúdo de Fenóis Totais } \\
\left(\mathrm{mg} \mathrm{planta}^{-1}\right)\end{array}$}} \\
\hline & & & & \\
\hline & \multicolumn{2}{|c|}{$\mathrm{P}\left(\mathrm{mg} \mathrm{kg}^{-1}\right.$ de solo $)$} & \multicolumn{2}{|c|}{$\mathrm{P}\left(\mathrm{mg} \mathrm{kg}^{-1}\right.$ de solo $)$} \\
\hline & 0 & 50 & 0 & 50 \\
\hline Inoculo misto & $11,3 \mathrm{bA}$ & $10,6 \mathrm{aA}$ & $20,4 \mathrm{aA}$ & 20,9 aA \\
\hline G. etunicatum & $11,4 \mathrm{bA}$ & $9,7 \mathrm{aB}$ & $19,3 \mathrm{abA}$ & $18,0 \mathrm{abA}$ \\
\hline G. Intraradices & $11,1 \mathrm{bA}$ & $10,8 \mathrm{aA}$ & $16,3 \mathrm{bA}$ & $17,6 \mathrm{bA}$ \\
\hline Sem fungo & 16,8 aA & $9,7 \mathrm{aB}$ & $3,5 \mathrm{cB}$ & $10,9 \mathrm{cA}$ \\
\hline
\end{tabular}

Médias seguidas pela mesma letra minúscula na coluna e letra maiúscula na linha não diferem entre si, pelo teste de Tukey a $5 \%$.

Rev. Bras. PI. Med., Campinas, v.16, n.1, p.1-9, 2014. 
evidenciando a capacidade dos FMAs em promover melhorias no estado nutricional da planta, o que é muito importante para o maior crescimento vegetal e rendimento de fenóis totais.

O conteúdo de nitrogênio e potássio na parte aérea do maracujazeiro doce foi influenciado tanto pelos tratamentos microbiológicos quanto pelas doses de fósforo (Tabela 4). Quando não se utilizou adubação fosfatada, as plantas inoculadas com as espécies G. etunicatum, G. intraradices e inóculo misto obtiveram conteúdo de nitrogênio superior ao tratamento sem fungo, com incremento de 404, 348 e $337 \%$, respectivamente. A média geral foi de 23,9 mg planta-1 ${ }^{-1}$ com variação de 6,20 a 31,2 mg planta ${ }^{-1}$ entre os tratamentos, sendo o menor valor encontrado no tratamento sem fungo e sem fósforo e o maior valor no tratamento inoculado com G. etunicatum e sem fósforo, nestes tratamentos foram encontrados o menor e maior valor de massa da matéria seca na dose 0 de $P$, respectivamente, mostrando a resposta positiva do nitrogênio sobre a produção da parte aérea do maracujazeiro doce.

Todos os tratamentos inoculados com FMAs apresentaram conteúdos de $\mathrm{K}$ maiores que o tratamento sem fungo (Tabela 4). Observou-se que o tratamento inoculado com $G$. etunicatum e sem adição de $P$, onde se verificou a maior produção de massa da matéria seca (Tabela 2 ), proporcionou incrementos de $1.500 \%$ no conteúdo de $\mathrm{K}$ em relação ao tratamento sem fungo e sem $P$.

Soares et al., (2005), trabalhando com Passiflora edulis inoculado com FMAs e dose de $\mathrm{P}$ (10 e $50 \mathrm{mg} \mathrm{kg}^{-1}$ ), observaram que não ocorreram diferenças significativas no conteúdo de $\mathrm{K}$ entre as mudas inoculadas, para a dose $10 \mathrm{mg} \mathrm{kg}^{-1}$, porém o conteúdo de $\mathrm{K}$ da parte aérea em relação ao controle (sem fungo e $10 \mathrm{mg} \mathrm{kg}^{-1}$ ) aumentou em 356,409 e $419 \%$ para inóculo nativo, G. clarum e G. fasciculatum, respectivamente. Corroborando Freitas et al., (2008), trabalhando com Mentha arvensis L. micorriza e fósforo, observaram que o conteúdo de $K$ na parte aérea da menta foi influenciado tanto pelos tratamentos microbiológicos quanto pelas doses de fósforo. Sem adição de fósforo a maior absorção de $\mathrm{K}$ foi encontrada nos tratamentos com G. clarum e G. margarita que proporcionaram incrementos de 139 e $142 \%$ em relação ao tratamento controle.

Verificou-se interação significativa para o teor e o conteúdo de fósforo na parte aérea do maracujazeiro doce entre tratamentos microbiológicos (fungos) e adubação fosfatada (Tabela 4). Na ausência da adubação fosfatada o teor e conteúdo de $\mathrm{P}$ na parte aérea do maracujazeiro doce, nos tratamentos inoculados com FMAs, foram superiores ao tratamento sem fungo. Observaramse incrementos de 329, 291 e 335\% para o teor de $P$ e $3.385,3.278$ e $2.978 \%$ para conteúdo de $P$ nos tratamentos inoculados com inóculo misto, G. etunicatum, G. intraradices, respectivamente. Marschner \& Dell (1994) verificaram que os FMAs podem ser responsáveis pela absorção de cerca de $80 \%$ do fósforo.

Em outras frutíferas também foi verificado maiores teores e conteúdos de fósforo em plantas micorrizadas. Trindade et al., (2001) observaram em mudas de Carica papaia do grupo solo e formosa que a inoculação com G. margarita, proporcionou maiores teores e conteúdos de fósforo na parte aérea, quando comparados ao tratamento sem inoculação. Chu et al., (2001) observaram que a média do conteúdo de $\mathrm{P}$ na parte aérea de Annona muricata L. inoculadas com Scutellospora heterograma foi de 6,1 mg planta-1 e inoculadas com Gigaspora sp. $5,5 \mathrm{mg} \mathrm{planta}^{-1}$ e que no tratamento não inoculado os valores foram inferiores, correspondendo a 0,7 mg planta ${ }^{-1}$.

Quando foi adicionado P, houve incremento no teor e conteúdo de $\mathrm{P}$ nos tratamentos inoculados com inóculo misto, G. etunicatum e no tratamento sem fungo (Tabela 4). Silva (2008) observou que o teor de fósforo na parte aérea de $P$. cincinnata com o inóculo G. etunicatum foi $81 \%$ superior ao tratamento sem fungo e com adubação de $P$ houve incremento de $69 \%$ no tratamento com inoculação.

No tratamento sem inoculação com FMAs, quando não foi adicionado fósforo, o teor desse nutriente na parte aérea foi $288 \%$ menor que no

TABELA 4. Conteúdo de $\mathrm{N}, \mathrm{P}$ e $\mathrm{K}$ e teor de $\mathrm{P}$ na parte aérea de plantas de maracujazeiro doce em função da inoculação com fungos micorrizicos e de adubação fosfatada.

\begin{tabular}{|c|c|c|c|c|c|c|c|c|}
\hline \multirow[t]{3}{*}{ Fungo } & \multicolumn{2}{|c|}{$\begin{array}{l}\text { Conteúdo de } \mathrm{N} \\
\left(\mathrm{mg} \mathrm{planta}^{-1}\right)\end{array}$} & \multicolumn{2}{|c|}{$\begin{array}{l}\text { Conteúdo de K } \\
\left(\text { mg planta }^{-1}\right)\end{array}$} & \multicolumn{2}{|c|}{$\begin{array}{l}\text { Teor de } P \\
\left(\mathrm{~g} \mathrm{~kg}^{-1}\right)\end{array}$} & \multicolumn{2}{|c|}{$\begin{array}{l}\text { Conteúdo de } \mathrm{P} \\
\text { (mg planta-1) }\end{array}$} \\
\hline & \multicolumn{2}{|c|}{$\mathrm{P}\left(\mathrm{mg} \mathrm{kg}^{-1}\right)$} & \multicolumn{2}{|c|}{$\mathrm{P}\left(\mathrm{mg} \mathrm{kg}^{-1}\right)$} & \multicolumn{2}{|c|}{$\mathrm{P}\left(\mathrm{mg} \mathrm{kg}^{-1}\right)$} & \multicolumn{2}{|c|}{$\mathrm{P}\left(\mathrm{mg} \mathrm{kg}^{-1}\right)$} \\
\hline & 0 & 50 & 0 & 50 & 0 & 50 & 0 & 50 \\
\hline Inoculo misto & $27,1 \mathrm{aA}$ & 27,0 aA & $30,8 \mathrm{bB}$ & $37,7 \mathrm{aA}$ & $2,92 \mathrm{aB}$ & $3,53 \mathrm{aA}$ & $4,88 \mathrm{aB}$ & $6,93 \mathrm{aA}$ \\
\hline G. etunicatum & $31,2 \mathrm{aA}$ & 28,0 aA & $43,1 \mathrm{aA}$ & $33,2 \mathrm{aB}$ & $2,66 \mathrm{aB}$ & $3,32 \mathrm{aA}$ & $4,73 \mathrm{aB}$ & $6,14 a b A$ \\
\hline G. intraradices & 27,8 aA & 25,3 aA & $32,9 \mathrm{bA}$ & 34,0 aA & 2,96 aA & 3,28 aA & $4,31 \mathrm{aB}$ & 5,34 bA \\
\hline Sem fungo & $6,2 \mathrm{bB}$ & $19,0 \mathrm{bA}$ & $2,7 \mathrm{cB}$ & $20,7 \mathrm{bA}$ & $0,68 \mathrm{bB}$ & $2,64 \mathrm{bA}$ & $0,14 \mathrm{bB}$ & $2,76 \mathrm{cA}$ \\
\hline
\end{tabular}

Médias seguidas pela mesma letra minúscula na coluna e letra maiúscula na linha não diferem entre si, pelo teste de Tukey a $5 \%$.

Rev. Bras. Pl. Med., Campinas, v.16, n.1, p.1-9, 2014. 
tratamento com adição de fósforo e as plantas nesse tratamento estavam com teor de $\mathrm{P}$ considerado deficiente para plantas de Passiflora alata, segundo Freitas et al., (2008).

Com os resultados obtidos é possível concluir que no processo de produção de mudas de Passiflora alata, a utilização de fungos micorrízicos arbusculares pode reduzir a utilização de adubo fosfatado. Conclui-se, ainda, que as espécies de fungos micorrízicos arbusculares estudadas proporcionaram incrementos nos conteúdos de fenóis totais, N, P e K e no teor de P na parte aérea das plantas de Passiflora alata.

\section{AGRADECIMENTO}

$\mathrm{CNPq}$

Os autores agradecem a FAPERJ e ao

\section{REFERÊNCIA}

ANDERSON, J.D..; INGRAM, J.S.I. Tropical soil biology and fertility. A handbook of methods. 2 Edição. Walling ford, UK CAB International. 1993. 171p.

ANJOS, E.C.T. et al. Produção de mudas de maracujazeirodoce micorrizadas em solo desinfestado e adubado com fósforo. Pesquisa Agropecuária Brasileira, v.40, n.4, p.345-51, 2005.

ARAIM G, et al. Root colonization by an arbuscular mycorrhizal (AM) fungus increases growth and secondary metabolism of Purple Coneflower, Echinacea purpurea (L.) Moench. Journal Agricultural and Food Chemistry, v.57, n.6, p.2255-8, 2009.

BETTI, A.H. K PROVENSI, G, FENNEr, R, KLIEMANN, M, HECKLER, A. P.M., MUNARI, I.M, FORNARI, P.E, GOSMANN, G., RATES, S.M.K Investigação da atividade ansiolítica/sedativa de uma fração de flavonóides e uma fração de saponinas purificadas de Passiflora alata Dryander (PASSIFLORACEAE). In: XII JORNADAS DE JOVENS PESQUISADORES DAASSOCIAÇÃO DE UNIVERSIDADES DO GRUPO MONTEVIDEO, 1, 2004, Curitiba.

BRESSAN, W. et al. Fungos micorrízicos e fósforo, no crescimento, nos teores de nutrientes e na produção do sorgo e soja consorciados. Pesquisa Agropecuária Brasileira, v.36, n.2, p.250- 60, 2001.

CAVALCANTE, U.M.T. et al. Influencia da densidade de fungos micorrízicos arbusculares na produção de mudas de maracujazeiro-amarelo. Pesquisa Agropecuária Brasileira, v.37, n.5, p. 643-49, 2002.

$\mathrm{CHU}$, E.Y. et al. Efeitos da inoculação micorrízica em mudas de gravioleira em solo fumigado e não fumigado. Pesquisa Agropecuária Brasileira, v.36, n.4, p.67180, 2001.

COPPENS, G., ECKENDRUGGE, D. Exploração da diversidade genética das Passifloras. VI Simpósio Brasileiro sobre a cultura do Maracujazeiro. Campos dos Goytacazes; UENF/UFRRJ. 25p. (Publicado em CD). 2003.

COSTA, C.M.C. et al. Influência de fungos micorrízicos arbusculares sobre o crescimento de dois genótipos de aceroleira (Malpighia emarginata D.C.). Pesquisa Agropecuária Brasileira, v.36, n.6, p.893-901, 2001.

D'EÇA, C.S.B.D., RODRIGUES, E.F., MARTINS, M.R., RODRIGUES, R.C.M. Efeito de diferentes concentrações de ácido giberélico sobre a germinação de sementes de maracujazeiro-doce (Passiflora alata Curtis). VI Simpósio Brasileiro sobre a cultura do Maracujazeiro. Campos dos Goytacazes; UENF/ UFRRJ. 4 p. (Publicado em CD). 2003.

EMBRAPA. Centro Nacional de Pesquisa de Solos (Rio de Janeiro, RJ). Sistema brasileiro de classificação de solos. 2. ed. - Rio de Janeiro : EMBRAPA-SPI, 306 p. 2006.

FREITAS, M.S.M. et al,. Produção e qualidade de óleos essenciais de Mentha arvensis em resposta à inoculação de fungos micorrízicos arbusculares. Pesquisa Agropecuária Brasileira, v.39, n.9, p.887894, 2004a.

FREITAS, M.S.M. et al. Crescimento e produção de fenóis em carqueja [Baccharis trimera (Less.) Dc.] em resposta a inoculação com fungos micorrízicos arbusculares, na presença e na ausência de adubação mineral. Revista Brasileira de Plantas Medicinais, v.6, n.3, p.30-34, 2004b.

FREITAS, M.S.M. et al. Crescimento e composição da menta em resposta à inoculação com fungos micorrízicos arbusculares e adubação fosfatada. Horticultura Brasileira, v.24,n.1, p.11-16, 2006.

FREITAS, M.S.M. et al. Mineral Deficiency in Passiflora alata Curtis: Viexin bioproduction Journal of Plant nutrition, v.31, n.4, p.1844-54, 2008.

GRACE, C., STRIBLEY, P. A safer procedure fot routine staining of vesicular-arbuscular mycorrhizal fungi. Mycological Research, v.95, n.9, p.1160-62, 1991.

JACKSON, M.L. Soil chemical analysis. New Jersey: Prentice Hall. 1965. 498p.

JONES JR., J.B., WOLF, B., MILLS, H.A. Plant Analysis Handbook: a practical sampling, preparation, analysis, and interpretation guide. Athens (USA): Micro-Macro Publishing, 213p. 1991.

KAPPOR, R. et al. Effects of arbuscular mycorrhiza and phosphorus application on artemisinin concentration in Artemisia annua L. Mycorrhiza, v.17, n.7, p.581-587, 2007.

KIRIACHEK, S.G., et al. Regulação do desenvolvimento de micorrizas arbusculares. Revisão de Literatura, Revista Brasileira Ciência do Solo, v.33, n.1, p.1-16, 2009.

MALAVOLTA, E., VITTI, G.C., OLIVEIRA, S.A. DE. Avaliação do estado nutricional das plantas: princípios e aplicações. 2.ed. Piracicaba: POTAFOS, 1997. 319p.

MANICA, I. Taxionomia - Anatomia - Morfologia. In: Manica, I. Brancher, A., Sanzonowics, C., Icuma, I.M., Aguiar, J.L.P. de, Azevedo, J.A. de, Vasconcellos, M.A. da S., Junqueira, N.T.V. Maracujá-doce: tecnologia de produção, pós-colheita, mercado. Cinco Continentes: Porto Alegre, 2005. p. 27-33.

MARSCHENER, H.; DELL, B. Nutrient uptake in mycorhizal symbiosis. Plant and Soil, Dordrecht, v.159, n.1, p.89-102, 1994.

MARTINS, M.R., PEREIRA JUNIOR, J.C., GOMES, J.J.A.,

Rev. Bras. PI. Med., Campinas, v.16, n.1, p.1-9, 2014. 
RODRIGUES, R.C.M., ARAÚJO, J.R.G. Avaliação de métodos de extração da mucilagem e de superação da dormência em sementes de maracujazeiro-doce (Passiflora alata Curtis). Anais do $6^{\circ}$ Simpósio Brasileiro sobre a Cultura do Maracujazeiro, Campos dos Goytacazes-RJ, UENF/UFRRJ. 4p. (Publicação em Compact disc) 2003.

MELLONI, R et al. Fósforo adicionado e fungos micorrízicos arbusculares no crescimento e nutrição mineral de limoeiro-cravo [Citrus limonia (L.) osbeck]. Revista Brasileira de Ciência do Solo, v.24, n.4, p767-75, 2000.

MENDES, A.D.R. et al. Produção de biomassa e de flavonóides totais por fava d'anta (Dimorphandra mollis Benth) sob diferentes níveis de fósforo em solução nutritiva. Revista Brasileira de Plantas Medicinais, v.7, n.2, p.7-12, 2005.

Ministério da Saúde (2009). http://portal.saude.gov.br/ portal/saude/profissional/ Acesso em 02 de outubro de 2009.

MIRANDA, J.C.C et al. Effects of soil and plant phosphorus concentrations on vesicular-arbuscular mycorrhiza in sorghum plants. New Phytologist, v.112, n. 4, p.40510.1989.

MIRANDA, J.C.C. HARRIS, P.J. Effects of soil phosphorus on spore germination and hyphal growth of arbuscular mycorrhizal fungi. New Phytologist, v.128, n.3, p.103108, 1994

MOREIRA, F.M.S.; SIQUEIRA, J.O. Microbiologia e bioquímica do solo. Lavras, UFLA, 626p. 2002.

NOGUEIRA, M.A., CARDOSO, E.J.B.N. Produção de micélio externo por fungos micorrízicos arbusculares e crescimento de soja em função de doses de fósforo. Revista Brasileira de Ciencia do Solo, v.24, n.3, p.329-38, 2000.

PARIS, F. DE. et al. Pharmacochemical study of aqueous extracts os Passilfora alata Drynder and Passiflora edulis Sims. Acta Farmacêutica Bonaerense, v.21, n.1, p.5-8, 2002.

PETRY, R.D. et al. Comparative pharmacological study on hydroethanol extracts of Passiflora alata and Passiflora edulis leaves. Phytotherapy Research, v.15, n.1, p.162-64, 2001.

PORTUGAL, E.P. Influência de fungos micorrízicos arbusculares, sistemas de cultivo e parâmetros pós-colheita na concentração de esteviosídeos e desenvolvimento de Stevia rebaudiana (Bert.). 2006. 114p. Tese (Doutorado) - Campinas, SP, Universidade Estadual de Campinas, Faculdade de Engenharia Agrícola.

PROVENSI, G. Investigação da atividade ansiolítica de Passiflora alata Curtis (Passifloraceae). 2007. 135p. Tese (Mestrado em Ciências Farmacêuticas) Porto Alegre, Universidade Federal do Rio Grande do Sul - UFRS.

SILVA, E.M. Condição micorrízica em espécies passiflora e efeito da simbiose na promoção do crescimento. 2008. 75p. Tese (Mestrado em Biologia de Fungos) - Universidade Federal de Pernambuco, Recife.

SILVA, M.A. et al. Crescimento de mudas de maracujazeirodoce (Passiflora alata Curtis) associadas a fungos micorrízicos arbusculares (Glomeromycota) Acta Botânica Brasílica, v.18, n.4, p. 981-85, 2004.

SIQUEIRA, J.O. et al. Effects of phosphorus on formation of the vesicular-arbuscular mycorhizal symbiosis. Pesquisa Agropecuária Brasileira, v.19, n.12, p.146574, 1984.

SMITH, S.E., READ, D.J. Mycorrhizal Symbiosis. Califórnia:Academic Press; 3 edition. 2008. 800p.

SOARES, A.C.F.et al. Arbuscular mycorrhizal fungi and the occurrence of flavonoids in roots of passion fruit seedlings. Scientia Agrícola, v.62, n. 4, p. 331-36, 2005.

TAIZ L., ZEIGER E. Plant Physiology. Redwood City (California): The Benjamin/Commings Publishing, 4 edition. 2008. 820p.

TOUSSAINT, P. et al. Arbuscular mycorrhizal fungi can induce the production of phytochemicals in sweet basilrrespective of phosphorus nutrition. Mycorrhiza, v.17, n.4, p.291-97, 2007.

TRINDADE, A. V.; SIQUEIRA, J. O.; ALMEIDA, F. P. Dependência micorrízica de variedades comerciais de mamoeiro. Pesquisa Agropecuária Brasileira, Brasília, v. 36, n. 12, p. 1485-1494, 2001.

WEBER, O.B. et al. Inoculação de fungos micorrízicos arbusculares e adubação fosfatada em mudas de cajueiro-anão-precoce. Pesquisa Agropecuária Brasileira, v.39, n.5, p 477-483, 2004.

Rev. Bras. PI. Med., Campinas, v.16, n.1, p.1-9, 2014. 